\title{
The Assessment of Deer (Cervus elaphus) Trophies
}

\author{
Marius COTTA ${ }^{1}$, Gelu Rareş OROIAN², Teofil OROIAN ${ }^{*}$ \\ 1)Faculty of Animal Science and Biotechnologies, University of Agricultural Sciences and Veterinary \\ Medicine, 3-5 Mănăștur Street, 400372 Cluj-Napoca, Romania \\ 2) Terapia-Ranbaxi SA, 124 Fabricii Street, 400640, Cluj Napoca, Romania \\ *Corresponding authors, e-mail: teoroian@yahoo.com
}

Bulletin UASVM Animal Science and Biotechnologies 73(1)/ 2016

Print ISSN 1843-5262; Electronic ISSN 1843-536X

DOI:10.15835/buasvmcn-asb: 11944

\begin{abstract}
The red deer (Cervus elaphus) population's potential for trophy value from the 34 Neagra and 35 Sălard hunting areas on the Northern slope of the Gurghiu Mountains has been analysed and evaluated, based on a number of 42 red deer trophies taken between 2000-2014. The trophies were evaluated using the C.I.C. method, which was adopted at the "Conseil International de la Chasse" in Berlin in 1937. A description of the C.I.C. method and the score for the 42 trophies is included in the study. The result of the analysis shows that $50 \%$ of the total number of trophies are high value trophies (gold and silver medal), indicating the remarkable overall quality of the red deer population in the research area.
\end{abstract}

Keywords: Cervus elaphus, red deer trophy, rod length, rosette circumference.

\section{INTRODUCTION}

Probably considered the most important European game species, the red deer's (Cervus elaphus) trophy evaluation has generated countless debates over time. Some of the proposed methods include: the Jaques Blanchard method, the A. Dyk method, the Carpathian method, the Nadler method and finally the C.I.C. method, which was adopted at the "Conseil International de la Chasse" congress in Berlin in 1937. This is currently the official evaluation method that is recognised and used for red deer trophy evaluation (Botezat, 1942). As for the previous methods, the Nadler method, named after the director of the Budapest Zoo was the most used, including during the Leipzig (Lipsca) Hunting Show in 1930. By comparison to the C.I.C. method, the Nadler method does not take into account the length of the tray tine and it had a different points system for the crown. The aim of this study was to estimate the red deer population potential regarding trophy value, on two hunting areas on the Northern slope of Gurghiu Mountains. In this respect, a number of 42 red deer trophies, taken between 2010-2014 from the Neagra and Sălard hunting areas were analyzed and evaluated.

\section{MATERIALS AND METHODS}

The 42 red deer trophies taken from the two hunting areas, were evaluated using the C.I.C method. This method was presented in detail in several publications by Cotta V. (1982 and Cotta et al.,2001), Neacsu (1982), Selaru (2000 and 2006), Comsia (1968). The C.I.C. method uses a formula that includes several measurements, beauty and penalty points. The result of this formula is the C.I.C. score of the trophy. A description of this formula follows:

\section{A.Measurements}

1. Antler's length: each beam (which is the main trunk of the antler from which the tines or rays 
protrude) is measured with measuring tape on the outside of the curve.

The measurements are taken in $\mathrm{cm}$ with a $1 \mathrm{~mm}$ precision. The goal is to obtain the highest length value for each antler through several tries. The measurement starts at the bottom of the coronet (the rosette of bone where the antler joins the skull) without pressing the measuring tape into the depression between the beam and coronet. It then follows the curves of the beam and when it reaches the crown it follows the back side of the longest ray. The average of the measurements for both beams is multiplied by a 0.5 coeficient and the result is recorded in the score sheet.

2. Brow tine: each tine is measured in $\mathrm{cm}$ with a $1 \mathrm{~mm}$ precision, starting from the upper part of the coronet up to the tip of the tine. If the brow tine is positioned higher $(4-5 \mathrm{~cm}$ from the coronet), the measurement starts from the point where the tine protrudes from the beam. The average of the measurements for both tines is multiplied by a 0.25 coeficient and the result is recorded in the score sheet.

3. Tray tine: each tine is measured on the outside of the curve, starting from the point where the tine protrudes from the beam. The average of the measurements for both tines is multiplied by a 0.25 coeficient and the result is recorded in the score sheet.

4. Circumference of coronets: is measured without pressing the measuring tape in the depressions created by the pearling, in $\mathrm{cm}$ with $1 \mathrm{~mm}$ precision.
The average of the measurements for both tines is multiplied by a 1 coeficient.

5. Circumference of the lower beams: is measured between the brow tine and the tray tine, where the beam is thinner. Each measurement has a 1 coeficient and is recorded (not the average).

6. Circumference of the upper beams: is measured same as above but between the tray tine and the crown. Each measurement has a 1 coeficient and is recorded (not the average).

7. Number of total tines: only tines over $2 \mathrm{~cm}$ count, measured from the point where they protrude from the beam to the tip of the tine. Naturally, broken tines are also counted. Those that were cut or artiicially added are not counted. Each tine counts for 1 point.

8. Weight: is measured with a $10 \mathrm{~g}$ precision on a dry trophy. If the skull is intact, $0.7 \mathrm{~kg}$ are subtracted, if the skull has been cut but the nasal bones are still present nothing is subtracted, and if only the upper jaws have been cut, $0.5 \mathrm{~kg}$ are subtracted.

If the trophy is evaluated 24 hours after it had been boiled, the subtracted weights are:

- for $4.0-6.0 \mathrm{~kg}$ trophies, subtract $0.3 \mathrm{~kg}$;

- for 6.01 - $8.0 \mathrm{~kg}$ trophies, subtract $0.4 \mathrm{~kg}$;

- for $8.01-10.0 \mathrm{~kg}$ trophies, subtract $0.5 \mathrm{~kg}$;

- for trophies over $10.01 \mathrm{~kg}$, subtract $0.6 \mathrm{~kg}$.

The final weight is multiplied by a 2 coefficient and is recorded.

\section{B.Beauty points}

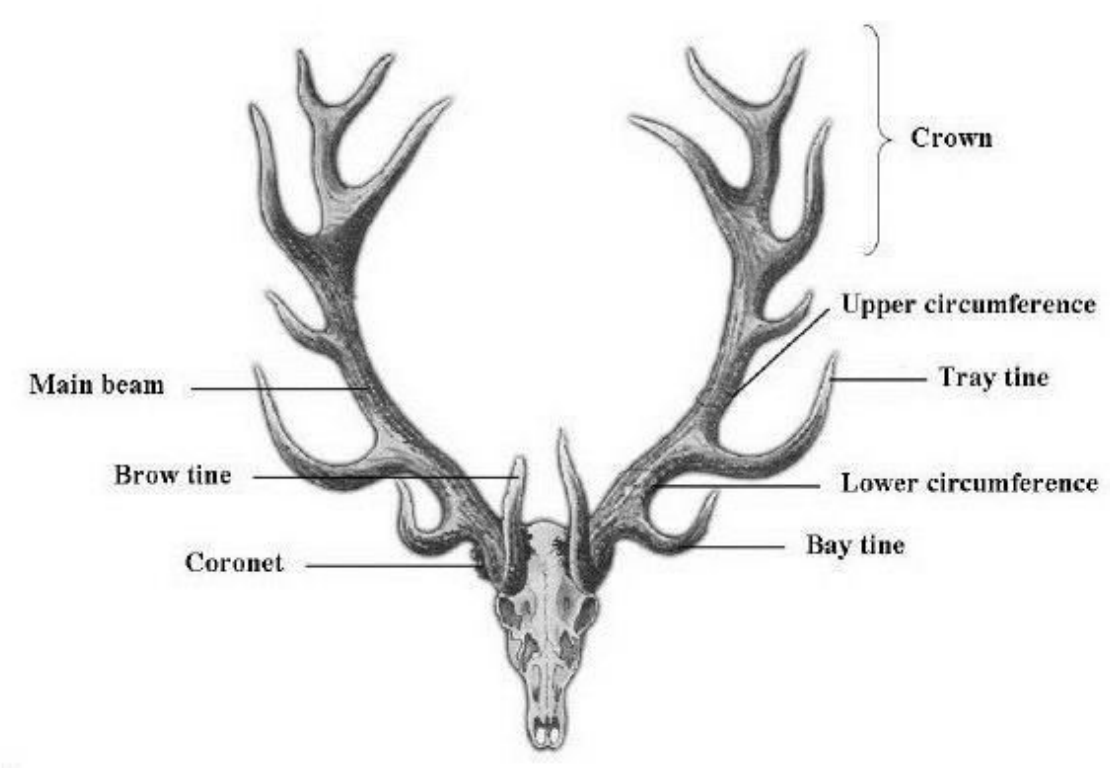

Fig. 1. The measured parameters of a red deer trophy (by Szederjei, 1960) 
9. Spread of the main beams: is measured at the longest distance between the 2 beams, on the inside of the beams, below the crowns. The measurement is made perpendicular to the median of the skull. The number of points granted is based on the ratio between the spread of the main beam and the average of the beam length as follows:

- under $60 \%$ - 0 points;

- 60-69.9\% - 1 point;

- 70-79.9\% - 2 points;

- over $80 \%$ - 3 points.

10. Colour: beauty points for colour are granted as follows:

- yellow or artificial colour: 0 points;

- light brown or gray: 0 - 0.5 points;

- brown: 1 point;

- dark brown: 1.5 points;

- dark brown - black: 2 points.

\section{Pearls:}

- beams with no pearls or weak pearls: 0 points;

- beams with medium pearls: 1 point;

- beam with heavy pearls: 2 points.

\section{The end of the tines:}

- blunt and unpolished: 0 points;

- sharp and unpolished: 1 point;

- sharp and polished: 2 points;

\section{Bay tines:}

- for short tines $2-10.0 \mathrm{~cm}$ :

0 points for 1 tine;

0.5 points for 2 tines.

- for medium tines $10.01-15.0 \mathrm{~cm}$ :

0.5 points for 1 tine;

1 points for 2 tines.

- for long tines over $15.01 \mathrm{~cm}$ :

1 point for 1 tine;

2 points for 2 tines.

14. Crown: depending on the number of tines in the crown and their length, up to 10 points can be granted. All the tines above the tray tine are considered if they are over $2 \mathrm{~cm}$.

Crown tines are grouped as follows:

- short tines - between $2-10 \mathrm{~cm}$;

- medium tines $-10.1-15 \mathrm{~cm}$;

- long tines - over $15.1 \mathrm{~cm}$.
The length of the crown tines is measured from the point where they protrude from the beam on the outside of the curve.

Depending on the number of tines in the crown and their grouping based on length mentioned above, the total score for the crown is calculated using an additional table.

\section{C.Penalty points}

Between $0-3$ points can be subtracted for visible asymmetry of the main beams, the crown, the brow tines or the bay tines, if these elements were not taken into account during the measurements. Broken tines are not penalised.

\section{RESULTS AND DISCUSSION}

The analyzed material consists of the 42 red deer trophies in the table below (Table 1). It should be noted that these red deer were taken in conformance with the approved harvest plan, so they include selection trophies as well as high value trophies.

By analyzing the results from the evaluation of these 42 red deer trophies, we have found the following two high value trophies: the Ronald Deppe trophy, hunted in 2014, evaluated at 225.5 points (Fig. 2.) and the Gherd Reifschneider trophy, hunted in 2008, evaluated at 224.45 points (Fig. 3.). It is worth mentioning that 3 trophies over 210 points are Gold medal, 18 trophies between 190-209.9 points are Silver medal, and 12 trophies between 170-189.9 are Bronze medal.

The first 10 trophies in descending order based on C.I.C. score follow:

It is worth mentioning that the two top trophies (225.5 points and 224.5 points) were taken in years following major beech crops in the fall of 2007 and 2013, respectively.

\section{CONCLUSION}

Considering that the harvest plan on each of the studied hunting areas was one high value trophy and two selection trophies each year, the high value trophies ( 3 Gold medals and 18 Silver medals) make up $50 \%$ of the total harvest, which shows a remarkable overall quality.

Aside from a very good genetic background of the red deer population in these 2 hunting areas, the biosystem is extremely favourable for this species. 
Table 1- Evaluation results of 42 red deer trophies

\begin{tabular}{|c|c|c|c|c|}
\hline Species & C.I.C. points & Hunting date & Hunter & Location \\
\hline Deer & 176 & 20.09 .00 & Lippmann F. & Germany \\
\hline Deer & 200.16 & 27.09 .01 & Lippmann F. & Germany \\
\hline Deer & 191.84 & 28.09 .01 & Lippmann F. & Germany \\
\hline Deer & 195.13 & 28.09 .02 & Lippmann F. & Germany \\
\hline Deer & 160.3 & 20.09 .03 & Ogie Iko & Germany \\
\hline Deer & 192.78 & 22.09 .03 & Lippmann F. & Germany \\
\hline Deer & 204.625 & 02.10 .03 & Lippmann F. & Germany \\
\hline Deer & 187.85 & 23.09 .05 & Wolbert Roland & Germany \\
\hline Deer & 198.48 & 29.09 .05 & Alberto Pratessi & Italy \\
\hline Deer & 135 & 14.12 .05 & Gliga Vasile & Reghin, Romania \\
\hline Deer & 183 & 0906 & Lippmann F. & Germany \\
\hline Deer & 186.2 & 0906 & Difelice G. & Italy \\
\hline Deer & 188.24 & 09.06 & Lippmann F. & Germany \\
\hline Deer & 169.23 & 10.07 & Roșianu Mihai & Romania \\
\hline Deer & 189.21 & 09.08 & Wolbert Roland & Germany \\
\hline Deer & 224.54 & 0908 & Gherd Reifschneider & Germany \\
\hline Deer & 188.16 & 0908 & Albert Keller & Switzerland \\
\hline Deer & 188.02 & 0909 & Joakhim Lohr & Germany \\
\hline Deer & 206.06 & 0909 & Meisberger Marc & France \\
\hline Deer & 182.2 & 09.09 & Heiko Lober & Germany \\
\hline Deer & 205.51 & 09.09 & Desaga Hubert & France \\
\hline Deer & 196.65 & 09.09 & Million J. & France \\
\hline Deer & 185.73 & 10.09 & Enzo Ide & Belgium \\
\hline Deer & 166.63 & 09.10 & Dietemar B. & Germany \\
\hline Deer & 216.74 & 0910 & Lippmann F. & Germany \\
\hline Deer & 198.22 & 0910 & Emhart H. & Germany \\
\hline Deer & 170.73 & 0910 & Viazzo Pietro & Italy \\
\hline Deer & 150.92 & 28.09 .11 & Gliga Vasile & Reghin, Romania \\
\hline Deer & 204.18 & 23.09 .12 & Poma Luca & Italy \\
\hline Deer & 166.35 & 23.09 .12 & Pitacco Paolo & Italy \\
\hline Deer & 119.79 & 22.09 .12 & De Maistre Enrico & Italy \\
\hline Deer & 202 & 25.09 .12 & Herbert Romen & Italy \\
\hline Deer & 184.65 & 27.09.12 & Dietmar Thaler & Austria \\
\hline Deer & 196.65 & 20.09 .13 & Poma Luca & Italy \\
\hline Deer & 203.13 & 21.09 .13 & Pitacco Paolo & Italy \\
\hline Deer & 197.78 & 22.09 .13 & Deorsola Francesco & Italy \\
\hline Deer & 191.03 & 22.09 .13 & Poma Luca & Italy \\
\hline Deer & 176.138 & 26.09 .14 & Uwe Bock & Germany \\
\hline Deer & 225.5 & 21.09 .14 & Deppe Roland & Germany \\
\hline Deer & 200.813 & 27.09 .14 & Florian Dany & Germany \\
\hline Deer & 196.176 & 26.09 .14 & Florian Dany & Germany \\
\hline Deer & 157.7 & 10.10 .14 & Dimitrie Sturdza & Ibănești, Romania \\
\hline
\end{tabular}




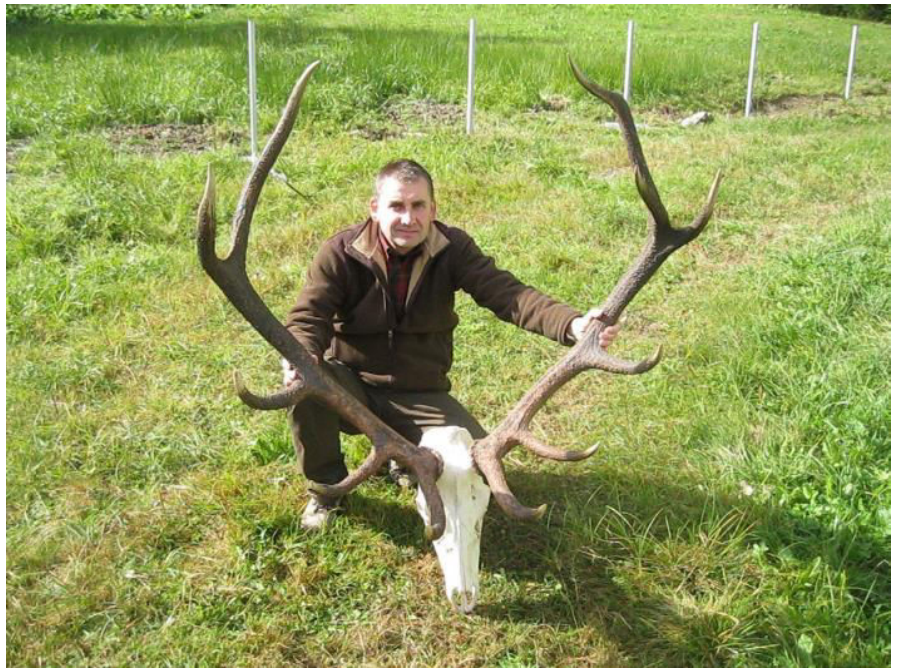

Fig. 2. The Ronald Deppe trophy, hunted in 2014, evaluated at 225.5 points (Original)

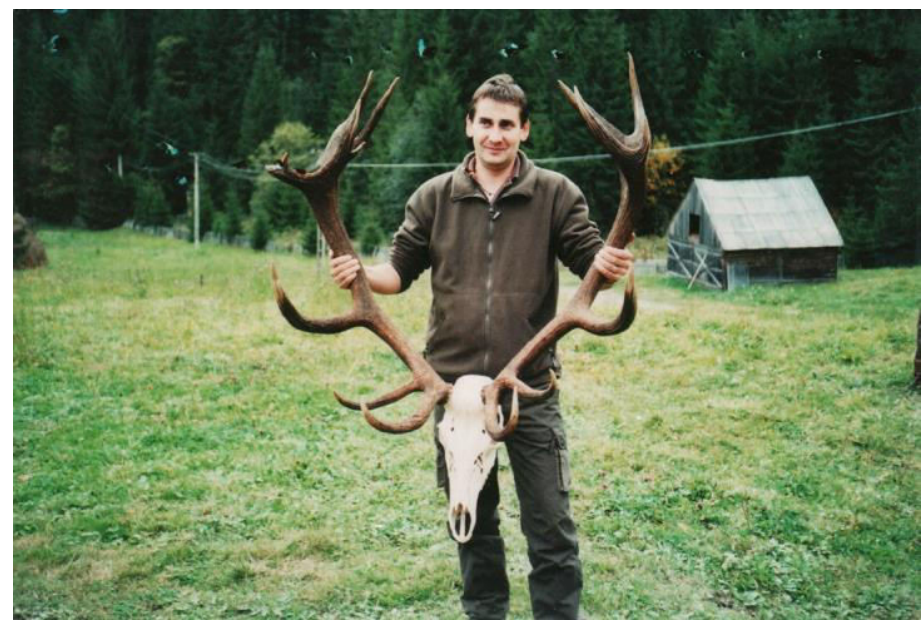

Fig. 3. The Gherd Reifschneider trophy, hunted in 2008, evaluated at 224.45 points (Original)

Table 2- The first 10 trophies in descending order based on C.I.C score

\begin{tabular}{cccc}
\hline No & C.I.C score & Year & Hunter \\
\hline 1 & 225.50 & 2014 & Roland Deppe \\
\hline 2 & 224.54 & 2008 & Gherd Reifschneider \\
\hline 3 & 216.74 & 2010 & Friedrich Lippmann \\
\hline 4 & 206.06 & 2009 & Marc Meisberger \\
\hline 5 & 205.51 & 2009 & Hubert Desaga \\
\hline 6 & 204.62 & 2003 & Friedrich Lippmann \\
\hline 7 & 204.18 & 2012 & Luca Poma \\
\hline 8 & 203.13 & 2012 & Paolo Pitacco \\
\hline 9 & 202.00 & 2012 & Derbert Romen \\
\hline 10 & 200.81 & 2014 &
\end{tabular}


Also the natural predation performed by a well established population of predators (brown bear, wolf and lynx) contributes to the vigour and health of the red deer population.

\section{REFERENCES}

1. Botezat E. (1942). Mecanica dezvoltării coarnelor la cerb. Rev. Carpaţi, No. 5, Cluj.

2. Comşia AM. (1968). Vânat românesc, Ed. Meridiane, Bucureşti.
3. Cotta V. (1982). Vânatul, Ed. Ceres, Bucureşti.

4. Cotta V, Bodea M, Micu I. (2001). Vânatul şi vânătoarea în România, Ed. Ceres, București.

5. Neacșu A, Popescu C, Nicolau C. (1982). Vânatul cu trofee, Ed. Ceres, București

6. Selaru N. (2000). Trofee de vânat, Ed. Ared, Bucureşti.

7. Selaru N. (2006). Trofee de vânat european, Ed. Cynegis, București.

8. Szederjei A. (1960). Szarvas, Mezőgazdasági Kiadó, Budapest. 